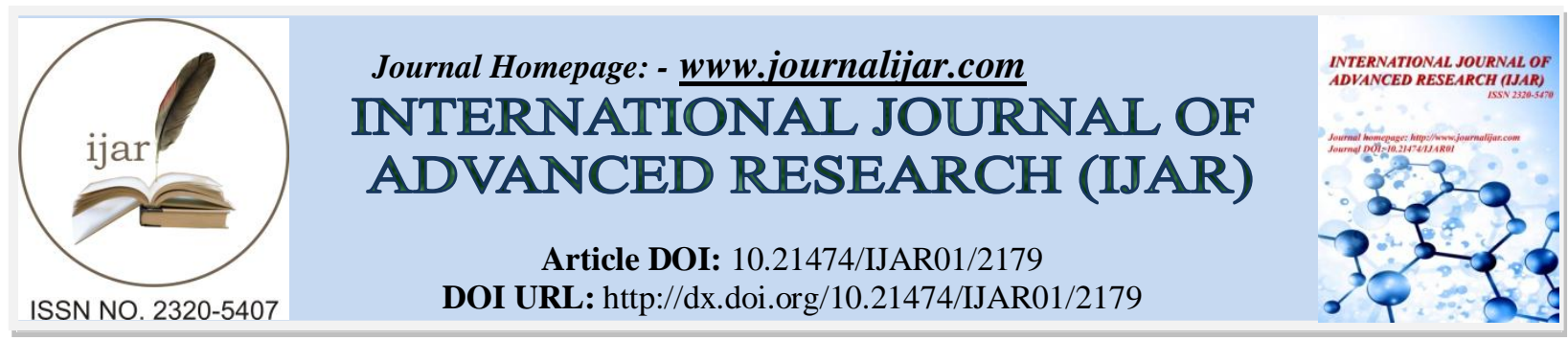

RESEARCH ARTICLE

\title{
SNEDDS (SELF-NANOEMULSIFYING DRUG DELIVERY SYSTEM) FORMULATION OF $\beta$ - CAROTENE IN OLIVE OIL (Olea europaea)
}

Erna Wulandari, Adella Clara Alverina and Ronny Martien.

Department of Pharmaceutics, Faculty of Pharmacy, Universitas Gadjah Mada, Sekip Utara, 55281 Yogyakarta, Indonesia.

\section{Manuscript Info}

Manuscript History

Received: 26 September 2016

Final Accepted: 29 October 2016

Published: November 2016

Key words:-

SNEDDS, $\beta$-carotene, olive oil, SLD.

\section{Abstract}

$\beta$-carotene was a powerful antioxidant with analgesic and antiinflammatory activity which could be exploited to increase immunity and prevent chronic and degenerative diseases. $\beta$-carotene was water insoluble and easily oxidised in water. These properties could be severe challenges for oral formulation. Therefore, the aim of the study was to formulate Self-Nanoemulsifying Drug Delivery System (SNEDDS) of $\beta$-carotene to facilitate oral delivery.

SNEDDS of $\beta$-carotene consisted of olive oil as the oil phase, Tween 80 as the surfactant and PEG 400 as the co-surfactant. Optimisation of the composition was achieved with simplex lattice design (SLD) method, software Design Expert ${ }^{\circledR}$ version 7.1.5. Optimum formula was determined by observing emulsification time and clarity of the nanoemulsions. Characterisation included physical stability in artificial gastric fluid (AGF), size and size distribution of the droplets and zeta potential value.

The results showed that formula with ratio of 1:8.1:1 of olive oil, Tween 80 and PEG 400, respectively, for $3 \mathrm{mg} / \mathrm{g}$ of $\beta$-carotene in SNEDDS formulation yielded the optimum result reflected by the emulsification time in AGF, $24.47 \pm 0.906$ seconds, transmittance value $91.17 \pm 0.450 \%$ and physically stable in AGF for 4 hours, droplet size $42.6 \mathrm{~nm}$ with polydispersity index 0.608 and zeta potential value $-38.7 \mathrm{mV}$.

Copy Right, IJAR, 2016,. All rights reserved.

\section{Introduction:-}

$\beta$-carotene is a potential antioxidant either in its native form or after being converted into vitamin A. Both act together as radical scavengers to prevent degenerative diseases such as cardiovascular, cancer, neurodegenerative, autoimmune diseases, rheumatoid arthritis, cataract and aging (Kasih, 2008, Pham-Huy, et al., 2008, Tapan, 2005). However, $\beta$-carotene is chemically instable. It also possesses low solubility in water, high melting point and low bioavailability (Qian, et al., 2012). Currently, it has been explored to develop emulsion formulation from $\beta$-carotene to tackle the challenge (Qian, et al., 2012, Silva, et al., 2011, Yuan, et al., 2008). Yet, the presence of water can reduce the stability of $\beta$-carotene (Gupta, et al., 2011), oxygen in water can reduce antioxidant activity (Sutresna, 2008) and water can also mediate the growth of bacteria and further it can increase the risk of bacterial 
contamination (Arisman, 2009). Hence, Self-Nanoemulsifying Drug Delivery System (SNEDDS) is a preferred method.

SNEDDS is defined as a formulation consists of oil, surfactant and co-surfactant which possesses the ability to spontaneously form nanoemulsion with droplet size less than $100 \mathrm{~nm}$ soon as contact with gastrointestinal fluid occurs. As a result, the dissolution and absorption increase and, finally, the bioavailability is improved (Nazzal, et al., 2002).SNEDDS can produce more stable preparation either biologically and chemically and without the presence of water, the volume of dosage form is reduced. It also eases the administration of dosage form. With its ability to form droplets with size within $100 \mathrm{~nm}$ range, the solubility of water insoluble drugs can be increased and physical stability can be improved. Further, intestinal permeation can be boosted to aid higher bioavailability (Rane and Anderson, 2008, Wasan, et al., 2009).

In this research, SNEDDS formulations were prepared using olive oil as the oil phase with consideration that antioxidant activity of olive oil can protect $\beta$-carotene from degradation and increase carotenoid absorption (Vissers, et al., 2004). The screening of suitable surfactant and co-surfactant was based on the results of the characterisation of the formulations. Initial characterisations were the emulsification time and clarity of the newly formed nanoemulsions. Further characterisations included physical stability of nanoemulsions in artificial gastric fluid (AGF), size and size distribution of nanoemulsion droplets and the zeta potential value. Improved delivery of $\beta$ carotene, compared with commercially available dosage form such as in tablet and capsules is the main aim of this research.

\section{Experimental methods:- \\ Materials:-}

$\beta$-carotene (Sigma, United States), olive oil (Brataco, Indonesia), Tween 80 (Kao, Japan), Tween 20 (Brataco, Indonesia), PEG 400 (Brataco, Indonesia), Propylene glycol (Brataco, Indonesia), Artificial gastric fluid (AGF) that consists of distilled water (Brataco, Indonesia), $\mathrm{NaCl}$ (Merck, Germany), hydrochloric acid 37 \% (Merck, Germany) and $\mathrm{NaOH}$ (Sigma, United States).

\section{Methods:-}

Initial screening:-

Initial screening was done to find the suitable composition of surfactant and co-surfactant. Olive oil was mixed with surfactant and co-surfactant in series of composition as seen in Table 1.

Table 1:- Composition of olive oil, surfactant and co-surfactant.

\begin{tabular}{|c|c|c|}
\hline Olive oil & Surfactant & Co-surfactant \\
\hline 1 & 1 & 1 \\
\hline 1 & 2 & 1 \\
\hline 1 & 3 & 1 \\
\hline 1 & 4 & 1 \\
\hline 1 & 5 & 1 \\
\hline 1 & 6 & 1 \\
\hline 1 & 7 & 1 \\
\hline
\end{tabular}

The formula was made by preparing the oil, surfactant (Tween 80 or Tween 20) and co-surfactant (PEG 400 or propylene glycol) based on the composition as shown in Table $1(5 \mathrm{~mL})$ in a vial and homogenised with magnetic stirrer for about 10 minutes followed by sonication for 10 minutes. Further mixing was aided by placing the vial in water bath at $45^{\circ} \mathrm{C}$ for 15 minutes. The final mixtures were left for 24 hours to be assessed the physical stability visually at room temperature. The composition which can maintain the stability means the combination of the composition is compatible.

Stable composition $(1 \mathrm{~mL})$ was added into water $(100 \mathrm{~mL})$ followed by stirring with magnetic stirrer $100 \mathrm{rpm}$ until clear and stable emulsion was formed. Clarity of the emulsion was assessed with spectrophotometer at $650 \mathrm{~nm}$. Droplets of nanoemulsion within nanometer size will have clear appearance as water. System with the lowest amount of surfactant which can form clear nanoemulsion was chosen as the promising candidate. 


\section{Determination of the best formulation:-}

Compositions of olive oil, surfactant and co-surfactant were designed with simplex lattice design with Design Expert ${ }^{\circledR}$ version 7.1.5. Each formula (4.0 gram) was prepared to contain $\beta$-carotene ( $\left.3.0 \mathrm{mg} / \mathrm{g}\right)$. The upper limit of olive oil is $13.61 \%$, Tween $8080.28 \%$ and PEG $40013.61 \%$. The lower limit of olive oil is $9.86 \%$, Tween 80 $76.53 \%$ and PEG $4009.86 \%$ and the results are 14 formulas as seen in Table 2.

Table 2:- SNEDDS formulations based on Design Expert optimisation

\begin{tabular}{|c|c|c|c|c|c|c|c|}
\hline \multirow[t]{2}{*}{ Run } & \multicolumn{3}{|c|}{ Composition (\%) } & \multicolumn{3}{|c|}{ Actual composition (g) } & \multirow{2}{*}{$\begin{array}{c}\beta- \\
\text { carotene } \\
(\mathrm{mg})\end{array}$} \\
\hline & Olive oil & Tween 80 & PEG 400 & Olive oil & Tween 80 & PEG 400 & \\
\hline 1 & 11.110 & 77.780 & 11.110 & 0.4444 & 3.1112 & 0.4444 & 12.0 \\
\hline 2 & 9.860 & 76.530 & 13.610 & 0.3904 & 3.0612 & 0.5444 & 12.0 \\
\hline 3 & 9.860 & 80.280 & 9.860 & 0.3904 & 3.2112 & 0.3944 & 12.0 \\
\hline 4 & 12.360 & 77.155 & 10.485 & 0.4944 & 3.0862 & 0.4194 & 12.0 \\
\hline 5 & 13.610 & 76.530 & 9.860 & 0.5444 & 3.0612 & 0.3944 & 12.0 \\
\hline 6 & 10.485 & 77.155 & 12.360 & 0.4194 & 3.0862 & 0.4944 & 12.0 \\
\hline 7 & 11.735 & 78.405 & 9.860 & 0.4694 & 3.1362 & 0.3944 & 12.0 \\
\hline 8 & 13.610 & 76.530 & 9.860 & 0.5444 & 3.0612 & 0.3944 & 12.0 \\
\hline 9 & 11.735 & 76.530 & 11.735 & 0.4694 & 3.0612 & 0.4694 & 12.0 \\
\hline 10 & 11.735 & 78.405 & 9.860 & 0.4694 & 3.1362 & 0.3944 & 12.0 \\
\hline 11 & 9.860 & 78.405 & 11.735 & 0.3944 & 3.1362 & 0.4694 & 12.0 \\
\hline 12 & 10.485 & 79.030 & 10.485 & 0.4194 & 3.1612 & 0.4194 & 12.0 \\
\hline 13 & 9.860 & 76.530 & 13.610 & 0.3944 & 3.0612 & 0.5444 & 12.0 \\
\hline 14 & 9.860 & 80.280 & 9.860 & 0.3944 & 3.2112 & 0.3944 & 12.0 \\
\hline
\end{tabular}

\section{SNEDDS preparation:-}

$\beta$-carotene (12.0 mg) was weighed and placed into a light-impermeable vial. Olive oil, Tween 80 and PEG 400 were added based on the composition obtained from Design Expert ${ }^{\circledR}$ software version 7.1.5. The mixtures were then homogenised with magnetic stirrer at $500 \mathrm{rpm}$ for 1 hour followed by 10 cycle of an hour sonication until clear mixtures were achieved. The mixtures were kept for 24 hours to ensure $\beta$-carotene was fully solubilised and miscible.

Initial physicochemical characterization:-

Initial characterisation included observation of emulsification time and clarity of the nanoemulsion.

Emulsification time was studied in AGF without pepsin. AGF $(250 \mathrm{~mL})$ at $37{ }^{\circ} \mathrm{C}$ was stirred constantly with magnetic stirrer $(3 \mathrm{~cm})$ at $100 \mathrm{rpm}$. SNEDDS formulation $(1.0 \mathrm{~mL})$ was added to the AGF. Emulsification time was calculated by observing the time needed from the addition of SNEDDS until it had been fully dispersed and nanoemulsion was formed.

Clarity of the nanoemulsions were observed by measuring the transmittance with spectrophotometer at $650 \mathrm{~nm}$. The closest the transmittance to water (supposed to be zero) means the smaller the droplets of the nanoemulsion and closer to nanometer range.

Determination of optimum SNEDDS formulation:-

Optimum SNEDDS formulation was determined with Design Expert® software version 7.1.5. Free variable was the composition of olive oil, surfactant and co-surfactant while the bound variable was the emulsification time and the clarity of nanoemulsion. The desired formula was the one with fast emulsification time and high level of clarity of the emulsion. 


\section{Verification of optimum formula:-}

SNEDDS were then prepared based on the optimum formula obtained from the software. Physicochemical characterisation and stability in AGF were assessed in the similar way as been done for 14 previous formulas. The results were then verified with single sample t-test analysis with Openstat ${ }^{\circledR}$ software.

\section{Characterisation of nanoemulsion:-}

Physical stability of nanoemulsion in AGF was studied by adding SNEDDS formulation (1.0 mL) into AGF (250 $\mathrm{mL}, 37^{\circ} \mathrm{C}$ ) mixed with magnetic stirrer at $100 \mathrm{rpm}$ until SNEDDS was fully dispersed. Homogenous emulsion was observed every 60 minutes for 4 hours. The unstable emulsion was marked by the increase of turbidity or aggregation.

Droplet size of the emulsion was observed by emulsifying SNEDDS (1.0 mL) in AGF (250 mL). Sample (5.0 mL) was taken from the emulsion and analysed with Particle Size Analyser (PSA). Data obtained from the measurement included average size, size distribution and deviation from the average.

Zeta potential of the droplets of the emulsion was conducted to observe the charge of the surface of the droplets. Zeta potential value was measured by diluting nanoemulsion ( 2 drops $)$ with water $(5 \mathrm{~mL})$ then mixed thoroughly. Sample (3 mL) was taken and analysed with PSA.

\section{Results and Discussion:-}

Screening of surfactant and co-surfactant:-

The screening was intended to discover the compatible combination of surfactant and co-surfactant with olive oil. This would accumulate the synergy effect of both substances to reduce the surface tension between oil and water to facilitate clear and homogenous nanoemulsion. The results could be seen in Table 3 .

Table 3:- Screening of surfactant and co-surfactant

\begin{tabular}{|c|c|c|c|c|}
\hline Composition & \multicolumn{4}{|c|}{ Surfactant and co-surfactant } \\
\hline $\mathrm{O}: \mathrm{S}: \mathrm{C}$ & $\begin{array}{l}\text { Tween } 80 \\
\text { PEG } 400\end{array}$ & $\begin{array}{c}\text { Tween } 80 \\
\text { PG }\end{array}$ & $\begin{array}{l}\text { Tween } 20 \\
\text { PEG } 400\end{array}$ & $\begin{array}{c}\text { Tween } 20 \\
\text { PG }\end{array}$ \\
\hline $1: 1: 1$ & Immiscible & Immiscible & Immiscible & Immiscible \\
\hline $1: 2: 1$ & Immiscible & Immiscible & Immiscible & Immiscible \\
\hline $1: 3: 1$ & Immiscible & Immiscible & Immiscible & Immiscible \\
\hline $1: 4: 1$ & Immiscible & Immiscible & Immiscible & Immiscible \\
\hline $1: 5: 1$ & Immiscible & Immiscible & Immiscible & Immiscible \\
\hline $1: 6: 1$ & Miscible* & Immiscible & Immiscible & Immiscible \\
\hline $1: 7: 1$ & Miscible* & Miscible* & Immiscible & Miscible* \\
\hline $1: 8: 1$ & Miscible* & Miscible* & Immiscible & Miscible* \\
\hline
\end{tabular}

*) chosen as the candidate

Surfactants chosen for the formulation were Tween 80 and Tween 20. Both were characterised by their high level of HLB, 15.0 and 16.7, respectively. Co-surfactants for the formulation were PEG 400 and propylene glycol with moderate level of HLB, 11.4 and 11.6. HLB value of co-surfactant would affect the SNEDDS system to form nanoemusion. Normally, HLB optimum for the system is between 12 and 20 (Costa, et al., 2012).

As seen in Table 3, Tween 80 was superior compared with Tween 20 as it could generate more formulation with better level of compatibility with the co-surfactant either PEG 400 or propylene glycol. Tween 80 is known to have more steric hindrance than Tween 20 formulation owing to its longer hydrocarbon chain to aid better stability of the emulsion (Murtiningrum, 2013). Besides, Tween 80 is also a derivate of oleic acid which is also a major substance in olive oil whereas Tween 20 has lauric acid as its main constituent. Olive oil showed better compatibility with Tween 80 as described by like dissolves like theory (Azeem, et al., 2009). Formulas from Table 3 which were marked as miscible were then emulsified in water to test if stable nanoemulsions could be achieved by measuring the transmittance. Clarity of the emulsions were presented in Table 4. 
Table 4:- Clarity of the emulsions

\begin{tabular}{|l|l|l|}
\hline Surfactant and co-surfactant & Composition O:S:C & Transmittance (\%) \\
\hline Tween 80 and PEG 400 & $1: 6: 1$ & 84.5 \\
\cline { 2 - 3 } & $1: 7: 1$ & $90.8^{*}$ \\
\cline { 2 - 3 } & $1: 8: 1$ & 96.9 \\
\hline Tween 80 and propylene glycol & & \\
& $1: 7: 1$ & 82.0 \\
\hline & $1: 8: 1$ & 90.6 \\
\hline Tween 20 and propylene glycol & & 65.6 \\
\hline
\end{tabular}

*) chosen for the next optimisation

System with lowest amount of surfactant that could generate nanoemulsion was chosen as the limit of the design of the formulation. Basically, clear visual appearance with more than $90 \%$ transmittance reflects the small size of the droplets hence can be chosen as the suitable candidates for the best formula (Costa, et al., 2012). Table 4 presented the result that mixture of olive oil, Tween 80 and PEG 400 with ratio 1:7:1 was able to produce nanoemulsion with transmittance higher than $90 \%$ thus it was considered as the base to determine upper and lower limit for the design of the formulation, as seen in Table 5.

Table 5:- Upper and lower limit of composition of free variable

\begin{tabular}{|l|l|l|}
\hline \multirow{2}{*}{ Free variable } & \multicolumn{2}{|c|}{ Composition (\%) } \\
\cline { 2 - 3 } & \multicolumn{1}{|c|}{ Lower limit } \\
\cline { 2 - 3 } & Upper limit & \multicolumn{1}{|c|}{ L.860 } \\
\hline & & 76.530 \\
\hline Olive oil & 13.610 & 9.860 \\
\hline PEG 400 80 & 80.280 & 13.610 \\
\hline
\end{tabular}

Determination of upper and lower limit met the requirement that the sum of upper limit of olive oil, lower limit of Tween 80 and lower limit of PEG 400 equaled to sum of lower limit of olive oil, upper limit of Tween 80 and lower limit PEG 400 and equaled to sum of lower limit of olive oil, lower limit of Tween 80 and upper limit of PEG 400 equaled to $100 \%$. Upper and lower limit were then used to generate the design for SNEDDS composition with Design Expert ${ }^{\circledR}$ software.

After 24 hours, all the 14 formulations appeared clear and miscible without aggregation and could be classified as stable mixtures. The results agree with the theory that $\beta$-carotene is soluble in oil and that SNEDDS can be used to tackle the problem related with solubility of $\beta$-carotene in water. It also proves that solubility of $\beta$-carotene can be enhanced by the presence of surfactant (Patel, et al., 2011).

\section{Characterisation of nanoemulsion:-}

Emulsification time:-

Emulsification time was observed to discover the easiness of nanoemulsion forming process of SNEDDS in simulated gastric fluid through mild agitation. Results could be seen in Table 6.

Table 6:- SNEDDS characterization.

\begin{tabular}{|l|l|l|l|l|l|l|}
\hline \multirow{2}{*}{ Run } & \multicolumn{2}{|l|}{ Composition (\%) } & $\begin{array}{l}\text { Emulsification time } \\
\text { (second) }\end{array}$ & $\begin{array}{l}\text { Transmittance } \\
(\%)\end{array}$ \\
\cline { 2 - 7 } & Olive oil & Surfactant & $\begin{array}{l}\text { Co- } \\
\text { surfactant }\end{array}$ & HLB & & \\
\hline 1 & 11.110 & 77.780 & 11.110 & 14.55 & 48.22 & 93.8 \\
\hline 2 & 9.860 & 76.530 & 13.610 & 14.46 & 28.96 & 82.1 \\
\hline 3 & 9.860 & 80.280 & 9.860 & 14.61 & 24.13 & 87.5 \\
\hline 4 & 12.360 & 77.155 & 10.485 & 14.57 & 53.31 & 87.1 \\
\hline 5 & 13.610 & 76.530 & 9.860 & 14.59 & 63.10 & 79.7 \\
\hline 6 & 10.485 & 77.155 & 12.360 & 14.50 & 21.44 & \\
\hline
\end{tabular}




\begin{tabular}{|l|l|l|l|l|l|l|}
\hline 7 & 11.735 & 78.405 & 9.860 & 14.60 & 55.10 & 90.7 \\
\hline 8 & 13.610 & 76.530 & 9.860 & 14.59 & 40.19 & $95.2^{*}$ \\
\hline 9 & 11.735 & 76.530 & 11.735 & 14.52 & 28.76 & 87.1 \\
\hline 10 & 11.735 & 78.405 & 9.860 & 14.60 & 37.85 & 91.7 \\
\hline 11 & 9.860 & 78.405 & 11.735 & 14.53 & 23.13 & 89.4 \\
\hline 12 & 10.485 & 79.030 & 10.485 & 14.58 & 29.28 & 89.6 \\
\hline 13 & 9.860 & 76.530 & 13.610 & 14.46 & 30.25 & 85.6 \\
\hline 14 & 9.860 & 80.280 & 9.860 & 14.61 & $16.13^{*}$ & 92.7 \\
\hline
\end{tabular}

*) Optimum formula

Normally, SNEDDS should be able to be fully dispersed in gastric fluid in less than one minute. Optimum formula based on emulsification time is the formula with the least time. Hence, based on Table 6, formula 14 was chosen as the best formula as the emulsification time was the fastest, 16.13 seconds. HLB value of the system was 14.61. It reflected the ability of the mixture of surfactant and co-surfactant to mediate the solubilisation of $\beta$-carotene in water by forming surface film between water and oil. Co-surfactant acts by slipping and creating voids in between surfactants arrangement so that it is swollen yet the fluidity increases to facilitate the forming of nanoemulsions. Higher HLB value means higher level of hydrophilicity thus faster emulsification time (Syamsuni, 2006). Emulsification time of each formulation was then analysed with Design Expert ${ }^{\circledR}$ software version 7.1.5. to find out the effect of each component or the interaction between them.

Graph of normal plot of residuals was made by plotting normal data of percentage of probability versus internally studentised residuals or the standard deviation of predicted response value and observed response value. Internally studentised residuals was obtained by dividing the difference of observed response and the predicted value with the standard deviation of difference of both values. Figure 1 shows that the data was distributed normally as reflected by the distribution of the data around and follow the diagonal normal line. It means data obtained from the experiments spread between two real value of the upper and lower limit. Further analysis was ANOVA with confidence level of $95 \%$, as seen in Table 7.

Table 7:- ANOVA result of emulsification time in AGF.

\begin{tabular}{|l|l|l|l|}
\hline \multirow{2}{*}{ Source } & \multirow{2}{*}{ F value } & p value & Note \\
\cline { 3 - 3 } & & Prob> F & \\
\hline & & & \\
\hline Model (linear mixture) & 8.01 & 0.0071 & Significant \\
\hline Lack of fit & 0.82 & 0.6154 & Not Significant \\
\hline
\end{tabular}

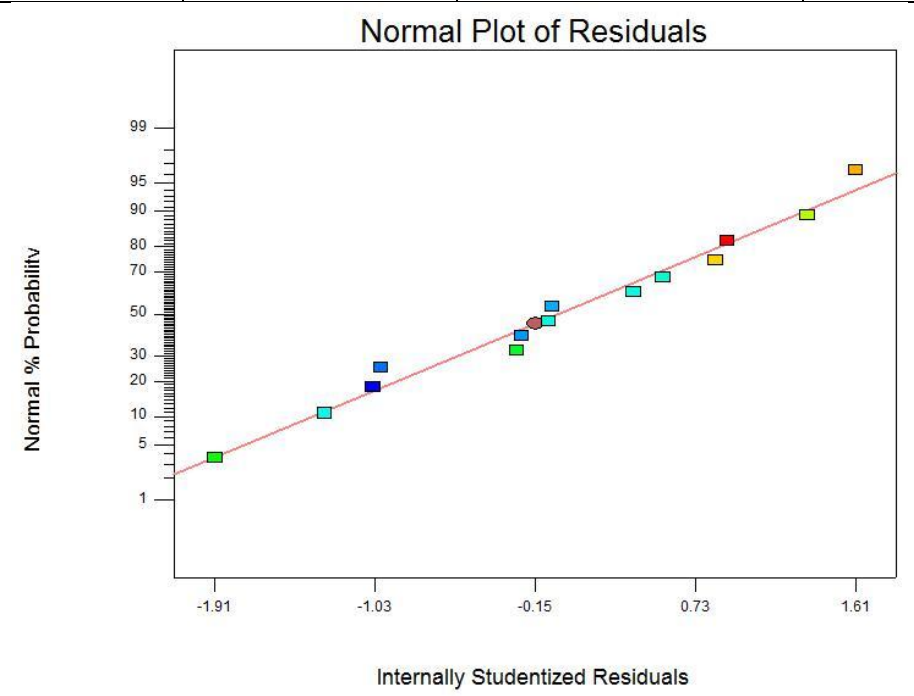

Figure 1:- Normal plot of residuals of emulsification time in AGF.

Linear mixture was the most suitable ANOVA method with $\mathrm{F}$ value 8.01 and $\mathrm{p}$ value is less than 0.05 . The model is denoted as significant which means alteration of the composition of each of the formula greatly affects the response, 
in this case is emulsification time. Lack of fit model generates the p value of more than 0.05 and it means that there is no significant difference between observed and predicted data. Based on data from Table 7 and SLD with Design Expert ${ }^{\circledR}$ software version 7.1.5., mathematic equation can be drawn (equation 1).

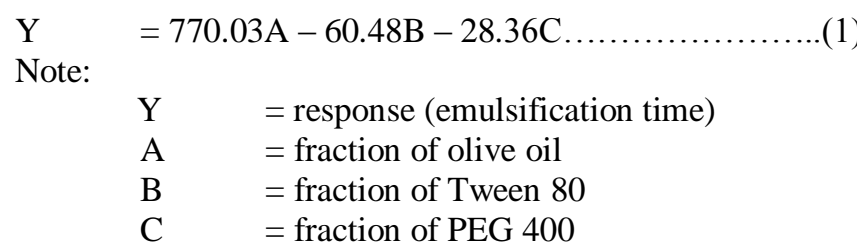

Positive value of the coefficient means the component gives positive/ synergic impact while negative means the effect is antagonist with the response (Huang, et al., 2004). The obtained equation exhibits that fraction of olive oil increases the response or slowing down the emulsification time, while Tween 80 and PEG 400 both reduce the emulsification time. Increasing the amount of olive oil in the formulation will result in lower proportion of surfactant and co-surfactant whereas both the latter are needed to facilitate the emulsification thus the emulsification time is longer and vice versa (Obitte, et al., 2011).

The higher the value of the coefficient means the bigger impact towards the response (Huang, et al., 2004). The equation shows that the fraction of olive oil possessed the biggest impact and PEG 400 impacted the least to alter the emulsification time as seen in Figure 2. It explains the relation of each component and emulsification time. Area in blue reflected the area with biggest impact towards emulsification time. Optimum response of emulsification time (16.13 seconds) was achieved with composition of $9.86 \%$ olive oil, $80.28 \%$ Tween 80 and $9.85 \%$ PEG 400 or 1:8.1:1 (formula 14).

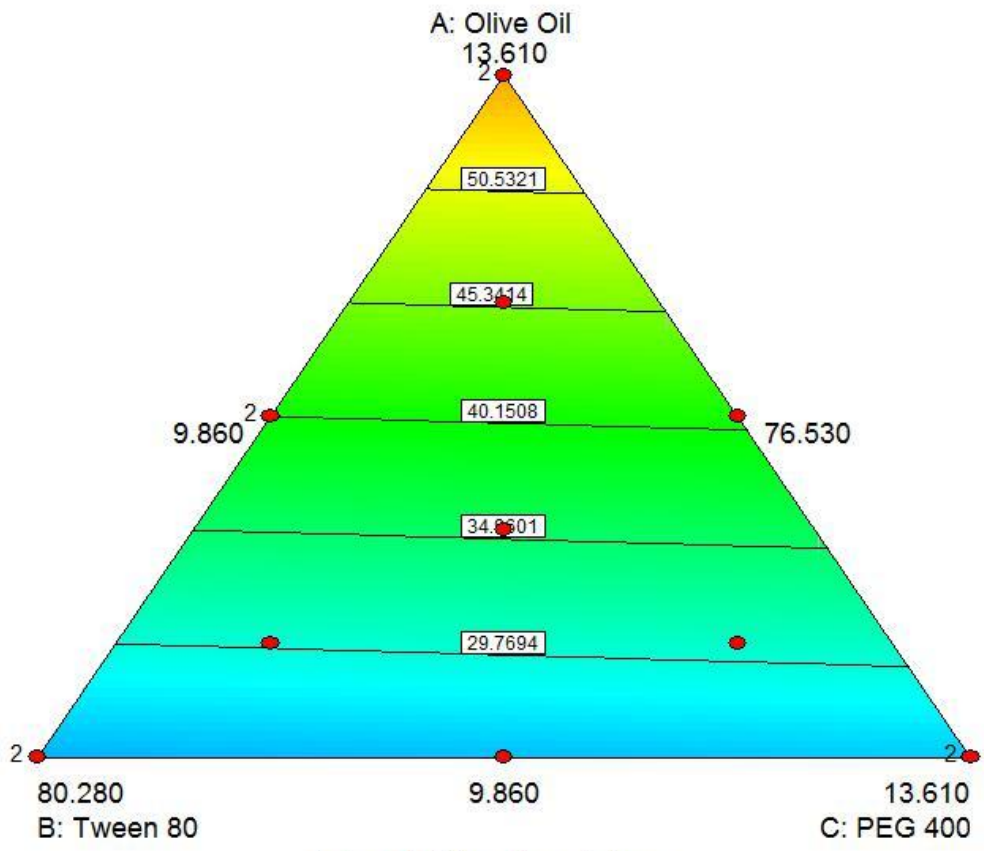

Emulsification Time

Figure 2:- Contour plot of emulsification time in AGF

\section{Clarity:-}

Clarity is one of the parameters to define nanoemulsion. Measurement of clarity can be done by observing the value of transmittance with spectrophotometer. The experiment was conducted in AGF medium to study the characteristic of nanoemulsion in gastric fluid. The result was shown in Table 6. 
Optimum clarity is achieved if the value of the transmittance is the highest possible or closer to $100 \%$ (Bali, et al., 2011). It is well accepted that transmittance value higher than $90 \%$ is considered as sufficient to be recognised as emulsion with nano-sized for the droplets of oil in water (Costa, et al., 2012). In contrast to the result of emulsification time which implied that formula 14 was the optimum one, based on the clarity the optimum formula was achieved by formula 8 with transmittance value $95.2 \%$.

Similar analysis with Design Expert ${ }^{\circledR}$ software version 7.1.5. to analyse the effect of each component towards turbidity or clarity of the emulsions. Figure 3 points that the data are distributed normally as seen in emulsification time results. Further statistical analysis with ANOVA is presented in Table 8.

Table 8:- ANOVA result of clarity of emulsion.

\begin{tabular}{|l|l|l|l|}
\hline Source & F value & p value & \multirow{2}{*}{ Note } \\
\cline { 3 - 4 } & & Prob> F & \\
\hline Model (linear mixture) & & & Significant \\
\hline Lack of fit & 4.79 & 0.0319 & Not significant \\
\hline
\end{tabular}

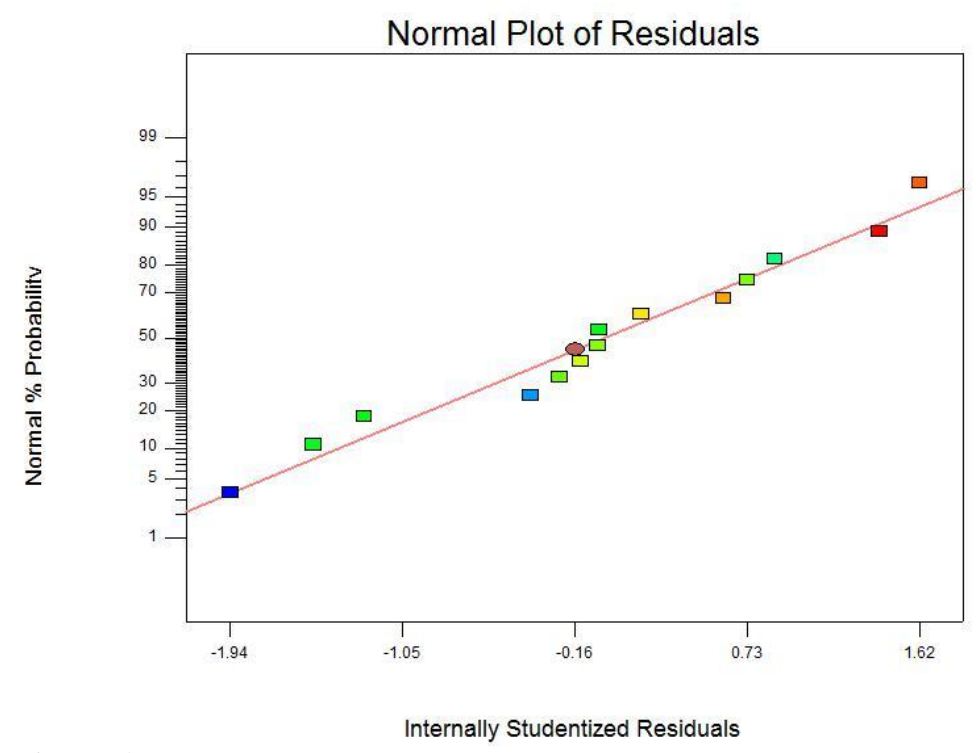

Figure 3:- Graph of normal plot of residuals clarity of nanoemulsions

F value of the linear mixture model in ANOVA analysis was 4.79 and p value was lower than 0.05 resulting the model was considered as significant which means even slight change in the proportion of the composition will significantly alter the turbidity of the emulsion. Lack of fit method showed p value was higher than 0.05 which meant no significant difference between observed and predicted data.

Based on Table 8 and SLD, mathematical equation can be drawn as seen in equation 2 below:

$$
\begin{aligned}
& \text { Y } \quad=117.31 \mathrm{~A}+110.92 \mathrm{~B}-97.54 \mathrm{C} \ldots . \\
& \text { Note: } \\
& \mathrm{Y}=\text { response clarity of the emulsion } \\
& \mathrm{A}=\text { fraction of olive oil in formulation } \\
& \mathrm{B}=\text { fraction of Tween } 80 \text { in formulation } \\
& \mathrm{C}=\text { fraction of PEG } 400 \text { in formulation }
\end{aligned}
$$

Similar interpretation method of the data as applied towards emulsification time was applied to assess the clarity and it showed that olive oil and Tween 80 increased the clarity. It is in contrast with the theory that states that oil will reduce the transmittance because the increase of oil proportion will increase the size of the droplets and induce the increase of turbidity or lower clarity. However, the phenomenon can be explained by the fact that olive oil can solubilize $\beta$-carotene thus facilitate the dissolution and the final effect is increase of transmittance or the clarity. 
Besides, it is also possible that the dominant factor is the presence of surfactant. Tween 80 as the surfactant works by reduce the surface tension between oil and water to produce small size of emulsion droplets (Dash, et al., 2015). PEG 400, based on the equation, will reduce the clarity of the nanoemulsion. It is as stated by some researcher that the ability of co-surfactant to increase the solubility of water insoluble drugs is followed by the increase of the size of the emulsion droplets (Zhao, et al., 2010). Based on the equation, it can be said that fraction of olive oil has the highest impact towards the clarity while PEG 400 the least.

Different compositions of olive oil, Tween 80 and PEG 400 generated different transmittance value, as seen in Figure 4. Area with yellow colour gave the highest transmittance. As the proportion of olive oil and Tween 80 increased, the transmittance increased while PEG 400 gave opposite result. Formula 8 with olive oil, Tween 80 and PEG 400 with ratio of $13.61 \%: 76.53 \%: 9.86 \%$ produced nanoemulsion with $95.2 \%$ transmittance and was considered as the best formula based on the clarity.

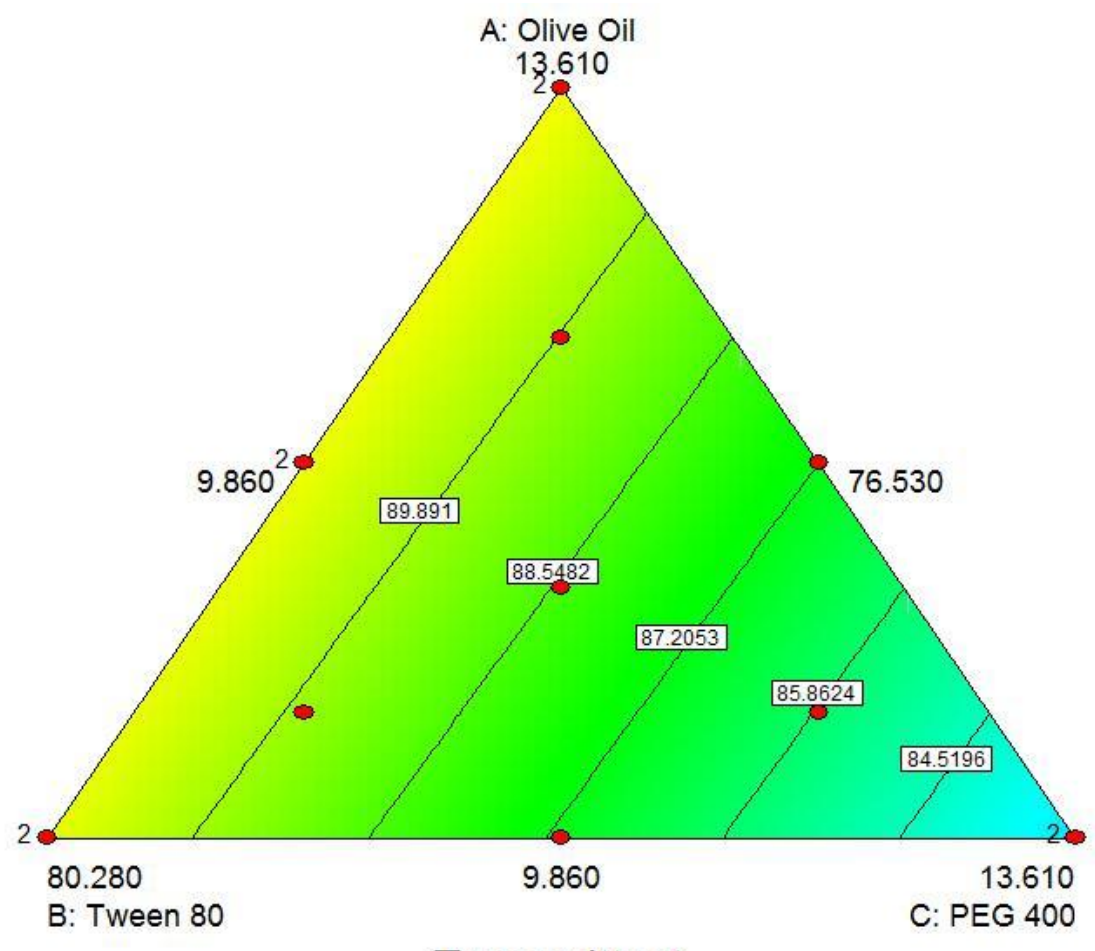

\section{Transmittant}

Figure 4:- Contour plot of the clarity of nanoemulsion

\section{Optimisation of the formula:-}

Optimisation of SNEDDS formulation was constructed with Design Expert® software version 7.1.5. with SLD method. The chosen bound variable, or responses, were evaluated towards the modification of the composition of olive oil, Tween 80 and PEG 400. Physical stability of nanoemulsion was no longer considered as the parameter as all of the formulas stayed stable during the experiment regardless of the formulation. The desired formula is the one with low emulsification time and high transmittance.

Based on Figure 5, the recommended formula was formula 14 with $9.86 \%$ olive oil, $80.28 \%$ Tween 80 and $9.86 \%$ PEG 400 with the highest desirability level of this experiment, 0.773 . Verification is needed to compare the obtained results and predicted results to verify the reproducibility. 


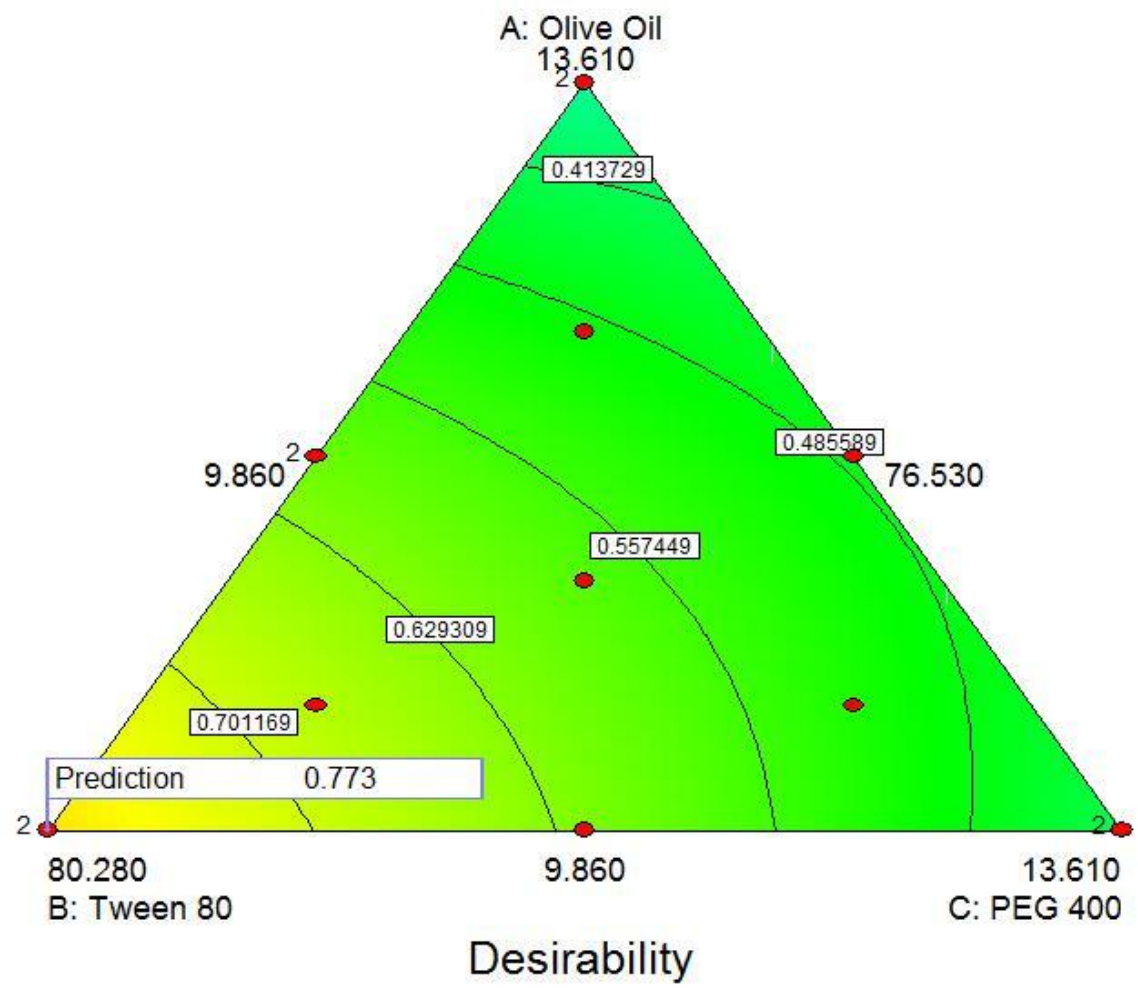

Figure 5:- Superimposed of contour plot emulsification time and clarity

The results of the experiment were verified with single sample t-test with OpenStat ${ }^{\circledR}$ and were presented in Table 9. $\mathrm{p}$ value from both of the responses was higher than 0.05 which implied that there was no significant difference between observed and predicted results. This result also supported the suggestion that the optimum formula passed the verification test.

Table 9:- Verification of optimum formula.

\begin{tabular}{|l|l|l|l|}
\hline Response & Predicted value & Observed value \pm SD & p value \\
\hline & & & \\
\hline Emulsification time & 24.58 & $24.47 \pm 0.906$ & 0.853 \\
\hline Transmittance & 90.99 & $91.17 \pm 0.450$ & 0.560 \\
\hline
\end{tabular}

\section{Characterisation of optimum formula:-}

\section{Physical stability of nanoemulsion in AGF:-}

Physical stability of nanoemulsion was observed to test the stability in AGF medium. The system is stable if there is no aggregation or precipitation during the testing period. Stable nanoemulsion is achieved if olive oil which contains $\beta$-carotene is still covered with surfactant and co-surfactant to prevent the leaking of $\beta$-carotene which further forms aggregates between each particles.

Physical stability was achieved by the suggested formulation in AGF at $37{ }^{\circ} \mathrm{C}$ for 4 hours. It implies that the formulation can stay for 4 hours in gastric fluid as the simulation of gastric emptying time which means nanoemulsion is able to stay in nanometre scale when absorbed from the intestine.

Stability is maintained because surfactant is able to reduce the surface tension and prevent coalescence between the droplets of emulsion. Component of emulsion with lower surface tension will spread and turn to be a continue phase. At the same time, surfactant molecules will draw themselves to the surface to prevent coagulation of dispersed phase. Non-ionic surfactants such as Tween 80 increase emulsion stability by forming inter surfaces film with high elasticity to keep distance between particles (Danov, et al., 2001). Co-surfactant will assist dispersion and 
dissolution of $\beta$-carotene by connecting surfactant molecules to support stability of reduction interface tension (Mou, et al., 2008).

\section{Size and size distribution of droplets of nanoemulsion:-}

Size of the droplets of nanoemulsion is a crucial factor as it can affect the dissolution of $\beta$-carotene from the dosage form (Parmar, et al., 2011). Size distribution is used as parameter to verify the uniformity and reliability of the method to prepare nanoemulsion. The result can be seen in Figure 6.

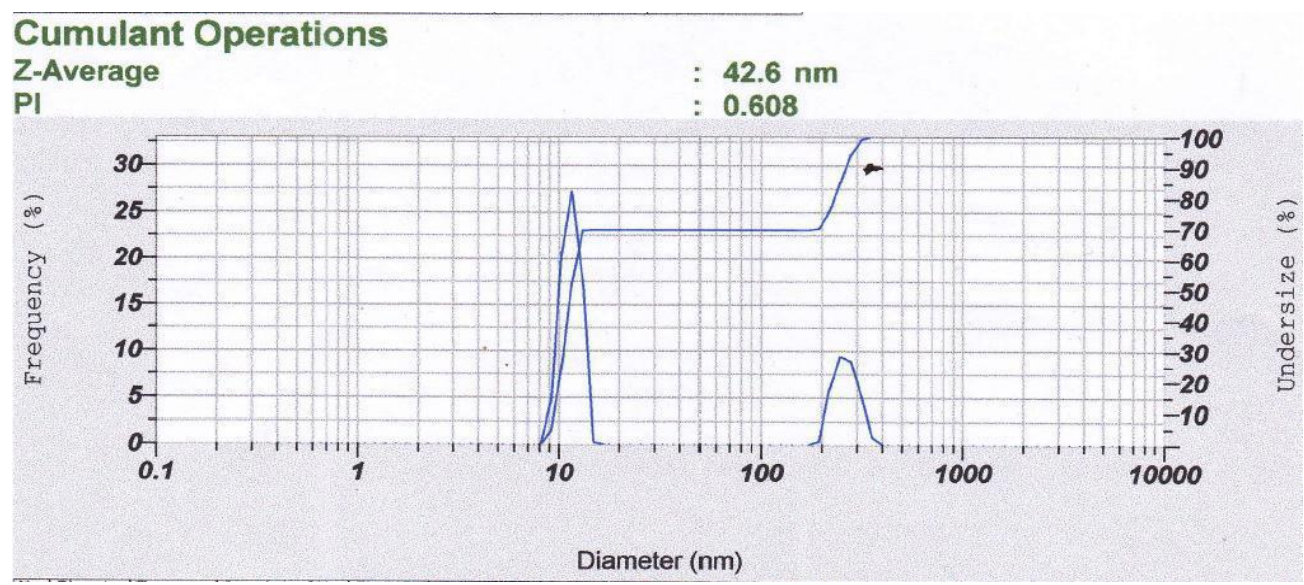

Figure 6:- Size and size distribution of nanoemulsion

Size of the droplets was analysed with particle size analyser and the result shows that average size of the droplet was $42.6 \mathrm{~nm}$, far below $100 \mathrm{~nm}$, limit of nanoemulsion size. The size is also smaller than $400 \mathrm{~nm}$, size of blood vessels which means nanoemulsion can be easily transported through circulatory system (Lalwani, et al., 2013, Larsen, et al., 2012, Thakur, et al., 2013). However, we can also notice that not all of the droplets were in the same size. For this purpose, polydispersity index (PI) was calculated to assess the uniformity of the droplet size, the closer the value to 0 means the system is more homogenous (Elsheikh, et al., 2012, Patel, et al., 2011). PI from the experiment was 0.608 thus it could be said that the droplets size was homogenous. Yet, further study is emerging to produce nanoemulsion with droplets size less than $100 \mathrm{~nm}$ for the whole formulation and lower PI value. One of the suggested method is to use combination of hydrophilic and lipophilic surfactants to produce smaller size of nanoemulsion droplets (Suhendra, et al., 2012).

\section{Zeta potential of droplets of nanoemulsion:-}

Zeta potential is measured to observe the surface charge of the droplets that is related with electrostatic interaction of the nanoparticles. Zeta potential reflects the balance ofrepulsion and attraction forces between the particles (Martin, et al., 1993). Average zeta potential value of the droplets of nanoemulsion was $-38.7 \mathrm{mV}$, as seen in Figure 7. The value is negative because of the presence of the free fatty acid as one of the component of olive oil and Tween 80 in SNEDDS formulation (Balakumar, et al., 2013). The value is considered optimum if more than \pm 30 $\mathrm{mV}$ (Singh and Liliard, 2009). Therefore, the droplets of nanoemulsion possesses sufficient balance of repulsion and attraction forces to prevent flocculation. 


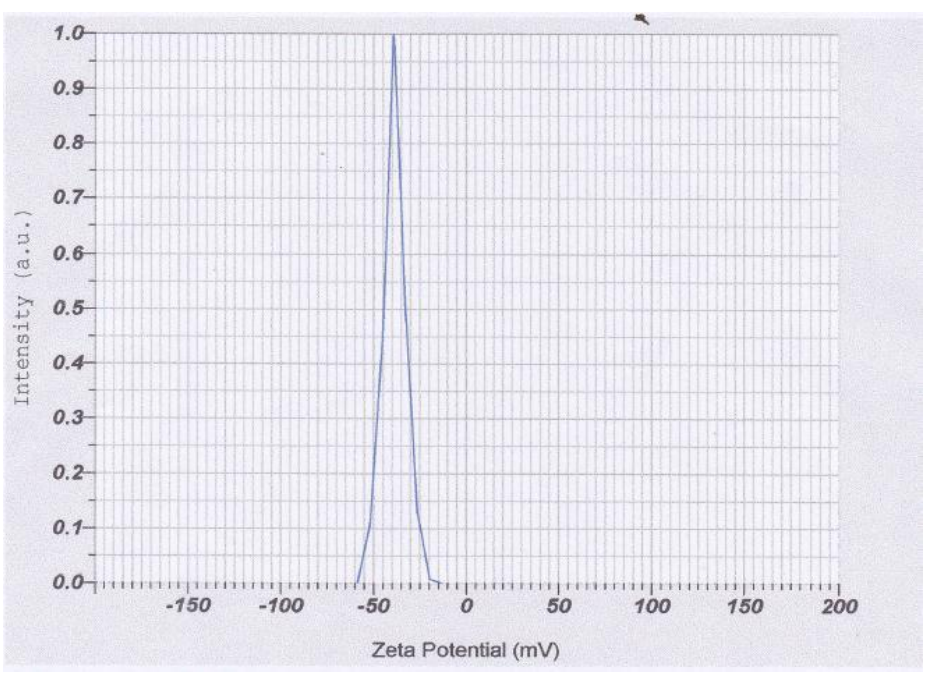

\section{Conclusion:-}

Figure 7:- Zeta potential value

SNEDDS of $\beta$-carotene with concentraction of $3 \mathrm{mg} / \mathrm{g}$ can be formulated with ratio of $9.860 \%: 80.280 \%$ : $9.860 \%$ or $1: 8,1: 1$ olive oil, Tween 80 and PEG 400, respectively. SNEDDS can produce nanoemulsion in $24.47 \pm 0.906$ seconds after contacting with artificial gastric fluid with $91.17 \pm 0.45 \%$ transmittance, sufficient stability at gastric fluid for 4 hours, average droplet size $42.6 \mathrm{~nm}$ with polydispersity index 0.608 and zeta potential value $-38.7 \mathrm{mV}$.

\section{References:-}

1. Arisman (2009): Keracunan Makanan : Buku Ajar Ilmu Gizi. Jakarta: Penerbit Buku Kedokteran EGC. 104.

2. Azeem, A., Rizwan, M., Ahmad, F. J., Iqbal, Z., Khar, R. K. and Aqil, M. A. (2009): Nanoemulsion Components Screening and Selection : a Technical Note. American Association of Pharmaceutical Scientists Pharmaceutical Science Technology, 10 (1): 69-76.

3. Balakumar, K., Raghavan, C. V., Selvan, N. T., Prasad, R. H. and Abdu, S. (2013): Self-Nanoemulsifying Drug Delivery System (SNEDDS) of Rosuvastatin Calcium : Design, Formulation, Bioavalability, and Pharmacokinetic Evaluation. Colloids and Surfaces B : Biointerfaces, 112: 337-343.

4. Bali, V., Ali, M. and Ali, J. (2011): Nanocarrier for the Enhanced Bioavailability of a Cardiovascular Agent : In Vitro, Pharmacodinamic, Pharmacokinetic, and Stability Assesment,. International Journal of Pharmaceutics, 403 (1): 46-56.

5. Costa, J. A., Lucas, E. F., Queiros, Y. G. C. and Mansur, C. R. E. (2012): Evaluation of Nanoemulsions in The Cleaning of Polymeric Resins. Colloids and Surfaces A: Physicochemical and Engineering Aspects, 415: 112118.

6. Danov, K. D., Kralchevsky, P. and Ivanov, I. B. (2001): Encyclopedic Handbook of Emulsion Technology. New York: Marcel Dekker. 621.

7. Dash, A. K., Singh, S. and Tolman, J. (2015): Pharmaceutics : Basic Principles and Application to Pharmacy Practice. San Diego: Academic Press. 186.

8. Elsheikh, M. A., Elnaggar, Y. S. R., Gohar, E. Y. and Abdullah, O. Y. (2012): Nanoemulsion Liquid Preconcentrates for Raloxifene Hidrochloride Optimization and In Vivo Appraisal. International Journal of Nanomedicine, 7: 3787-3802.

9. Gupta, S., Chavan, S. and Sawant, K. K. (2011): Self-Nanoemulsifying Drug Delivery System for Adefovir Dipivoxil: Design, Characterization, in Vitro and ex Vivo Evaluation. Colloids and Surfaces A : Physicochemical and Engineering Aspects, 392: 145-155.

10. Huang, Y. H., Zhang, S. H., Zhen, R. X., Xu, X. D. and Zhen, Y. S. (2004): Asiaticoside inducing Apoptosis of Tumor Cells and Enhancing Anti-Tumor Activity of Vincristine. AiZheng, 23: 1599-1604.

11. Kasih, M. A. A. L. (2008): Khasiat Warna-Warni Makanan. PT Gramedia Pustaka Utama.

12. Lalwani, J. T., Thakkar, V. T. and Patel, H. V. (2013): Enhancement of Solubility and Oral Bioavailability of Ezetimibe by A Novel Solid Self-Nanoemulsifying Drug Delivery System (SNEDDS). International Journal of Pharmacy and Pharmaceutical Science, 5 (3): 513-522. 
13. Larsen, A. T., Ogbonna, A., Abu-Rmaileh, R., Abrahamsson, B., Østergaard, J. and Müllertz, A. (2012): SNEDDS Containing Poorly Water Soluble Cinnarizine; Development and in Vitro Characterization of Dispersion, Digestion and Solubilization. Pharmaceutics, 4: 641-665.

14. Martin, A., Bustamante, P. and Chun, A. H. C. (1993): Physical Pharmacy. Philadelphia: Lea and Febiger.

15. Mou, D., Chen, H., Du, D., Mao, C., Wan, J., Xu, H. and Yang, X. (2008): Hydrogel-thickened Nanoemulsion System for Topical Delivery of Lipophilic Drugs. International Journal of Pharmaceutics, 353: 270-276.

16. Murtiningrum, S., Z. L., Cepeda, G. N., dan Olong, N., 2013, S (2013): Stabilitas Emulsi Buah Merah (Pandanus Conoideus L) pada Berbagai Nilai Hydrophile-Liphophile Balance (HLB) Pengemulsi. Jurnal Teknologi Industri Pertanian, 23 (1): 34.

17. Nazzal, S., Smalkyukh, I. I., Lavrentovich, O. D. and Khan, M. A. (2002): Preparation and In Vitro Characterization of An Eutectic Based Semisolid Self-Nanoemulsifying Drug Delivery System of Ubiquinone : Mechanism and Progress of Emulsion Formation. International Journal of Pharmaceutics, 235: 247-265.

18. Obitte, N. C., Ofokansi, K. C., Nzekwe, I. T., Esimone, C. O. and Okoye, I. E. (2011): Self-Nanoemulsifying Drug Delivery Systems Based on Melon Oil and its Admixture with a Homolipid from Bos indicus for the Delivery of Indomethacin. Tropical Journal of Pharmaceutical Research, 10 (3): 300.

19. Parmar, N., Singla, N., Amin, S. and Kohli, K. (2011): Study of Cosurfactant Effect on Nanoemulsifying Area and Development of Lecarnidipine Loaded (SNEDDS) Self-Nanoemulsifying Drug Delivery System, Colloids and Surfaces. Biointerfaces, 86: 327-338.

20. Patel, N. D., Patel, K. V., Panchai, L. A., Shukla, A. K. and Shelat, P. K. (2011): An Emerging Technique for Poorly Soluble Drugs: Self Emulsifying Drug Delivery Systems. International Journal of Pharmaceutical and Biological Research, 2 (2): 621-629.

21. Pham-Huy, L. A., He, H. and Pham-Huy, C. (2008): Free Radical, Antioxidants in Disease and Health. International Journal of Biomedical Science, 4 (2): 89-96.

22. Qian, C., Decker, E. A., Xiao, H. and McClements, D. J. (2012): Inhibition of B-carotene Degradation in Oil-inwater Nanoemulsions : Influence of Oil-soluble and Water-soluble Antioxidants. Food Chemistry, 135: 10361043.

23. Qian, C., Decker, E. A., Xiao, H. and McClements, D. J. (2012): Nanoemulsion Delivery Systems : Influence of Carrier Oil on B-carotene Bioaccessibility. Food Chemistry, 135: 1440-1447.

24. Rane, S. S. and Anderson, B. D. (2008): What Determines Drug Solubility in Lipid Vehicles: Is it Predictable? Advanced Drug Delivery Reviews, 60: 638-656.

25. Silva, H. D., Cerquira, M. A., Souza, B. W. S., Ribeiro, C., Avides, M., Quintas, M. A. C., Coimbra, J. S. R., Carneiro-da-Cunha, M. G. and Vicente, A. A. (2011): Nanoemulsions of Beta Carotene Using A High-Energy Emulsification - Evaporation Technique. Journal of Food Engineering, 102 (2): 130-135.

26. Singh, B. and Liliard, J. W. (2009): Nanoparticle Based Targeted Drug Delivery. Experimental and Molecular Pathology, 86 (3): 215-223.

27. Suhendra, L., Raharjo, S., Hastuti, P. and Hidayati, C. (2012): Formulasi dan Stabilitas Mikroemulsi o/w sebagai Pembawa Fucoxanthin. Agritech, 32 (3): 230-239.

28. Sutresna, N. (2008): Kimia. Bandung: Grafindo Media Pratama. 100.

29. Syamsuni, H. (2006): Farmasetika Dasar dan Hitungan Farmasi. Jakarta: EGC.

30. Tapan, E. (2005): Seri Kesehatan Keluarga: Kanker, Antioksidan, dan Terapi Komplementer. Jakarta: PT Elex Media Komputindo.

31. Thakur, A., Walia, M. K. and Kumar, S. L. H. (2013): Nanoemulsion in Enhancement of Bioavailability of Poorly Soluble Drugs : A Review. Pharmacophore, 4 (1): 15-19.

32. Vissers, M. N., Zook, P. L. and Katan, M. B. (2004): Bioavailability and Antioxidant Effect of Olive Oil Phenols in Human : A Review. European Journal of Clinical Nutrition, 58 (6): 955-965.

33. Wasan, E. K., Bartlett, K., Gershkovich, P., Sivak, O., Banno, B., Wong, Z., Gagnon, J., Gates, B., Leon, C. G. and Wasan, K. M. (2009): Development and Characterization of Oral Lipid-based Amphotericin B Formulations with Enhanced Drug Solubility, Stability and Antifungal Activity in Rats Infected with Aspergillus fumigatus or Candida albicans. International Journal of Pharmaceutics, 372: 76-84.

34. Yuan, Y., Gao, Y., Mao, L. and Zhao, J. (2008): Analytical Methods Optimisation of Conditions for the Preparation of Beta Carotene Nanoemulsions Using Response Surface Methodology. Food Chemistry, 107 (3): 1300-1306.

35. Zhao, Y., Wanga, C., , Chow, B., Albert H. L., Ren, K., Gong, T. and Zhang, Z. (2010): Self-Nanoemulsifying Drug Delivery System (SNEDDS) for Oral Delivery of Zedoary Essential Oil: Formulation and Bioavailability Studies. International Journal of Pharmaceutics, 383: 170-177. 